Hueck, K. (1972): As florestas da América do Sul: ecologia, composição e importância econômica. São Paulo: Polígono. 466p.

HuFFoRD, K. M. and J. L. HAMrICK (2003): Viability selection at three early life stages of the tropical tree, Platypodium elegans (Fabaceae, Papilionoideae). Evolution 57: 518-526.

MMA - Ministério do Meio Ambiente. (2010): Espécies da flora brasileira ameaçadas de extinção e com deficiência de dados. Instrução Normativa 06/2008. Disponível em: <www.mma.gov.br> Accessed: October 10, 2010.

PAtreze, C. M., and S. M. Tsai (2010): Intrapopulational genetic diversity of Araucaria angustifolia (Bertol.) Kuntze is different when assessed on the basis of chloroplast or nuclear markers. Plant Systematics and Evolution 284: 111-122.

Roberson, A., P. M. Hollingsworth, C. J. Kattle, R. A. ENNOS and M. F. GARDNER (2004): Characterization of nuclear microsatellites in New Caledonia Araucaria species. Molecular Ecology Notes 4: 62-63.

Salgueiro, F., H. Caron, M, I. F. Souza, A. Kremer and R. MARGIS (2005): Characterization of nuclear microsatellite loci in South American Araucariaceae species. Molecular Ecology Notes 5: 256-258.

Sant'Anna, C. S., A. M. Sebbenn, G. H. F. Klabunde, R. Bittencourt, R. O. Nodari, A. Mantovani and M. S. REIS (2013): Realized pollen and seed dispersal within a continuous population of the dioecious coniferous Brazilian Pine (Araucaria angustifolia (Bertol.) Kuntze). Conservation Genetics 14: 601-613.
Schmidt, A. B., A. Y. Ciampi, M. P. Guerra and R. NodARI (2007): Isolation and characterization of microsatellite markers for Araucaria angustifolia (Araucariaceae). Molecular Ecology Notes 7: 340-342.

Scott, L. J., M. Shepherd and R. J. Henry (2003): Characterization of highly conserved microsatellite loci in Araucaria cunninghammi and related species. Plant Systematics and Evolution 236: 115-123.

SEBbEnN, A. M. (2006): Sistemas de reprodução em espécies tropicais e suas implicações para a seleção de árvores matrizes para reflorestamentos ambientais. In: Pomar de sementes de espécies florestais nativas. HigA, A. R. and L. D. Silva (Eds.). Curitiba: FUPEF. p. 93-138.

Silva, C. V. and M. S. REIS (2009): Produção de pinhão na região de Caçador, SC: aspectos da obtenção e sua importância para comunidades locais. Ciência Florestal 19: $363-374$.

Stefenon, V. M., O. Gailing And R. Finkeldey (2007): Genetic structure of Araucaria angustifolia (Araucariaceae) populations in Brazil: implications for the in situ conservation of genetic resources. Plant Biology 9: 516-525.

Vidolin, G. P., D. B. Batista and A. WANDEMBRuck (2011): Landscape valuation based on the ecological requirements of Tayassu pecari and Tapirus terrestris a forest with araucaria, in Paraná State, Brazil. Ciência Florestal 21: $505-515$.

WEIR, B. S. (1996): Genetic Data Analysis II: Methods for discrete population genetic data. Sunderland: Sinauer Associaties. 376p.

WRIGHT, S. (1943): Isolation by distance. Genetics 28: 114-138.

\title{
Different diversity measures and genetic traits reveal different species- genetic diversity relationships: A case study in forest tree communities
}

\author{
By F. BergmanN ${ }^{1), *}$, H.-R. Gregorius ${ }^{1,2)}{ }^{1,2}$ D. KownatZKi ${ }^{3)}$ and Chr. WehenkeL ${ }^{4)}$
}

(Received 18 ${ }^{\text {th }}$ April 2012)

\begin{abstract}
Relationships between species diversity and genetic diversity, the two most important elements of biodiversity, have recently attracted considerable interest in the field of community genetics. The present study con-

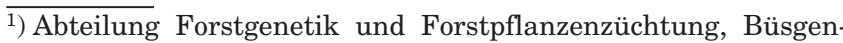
weg 2, D-37075 Göttingen, Germany.

2) Institut für Populations- und ökologische Genetik, Am Pfingstanger 58, D-37075 Göttingen, Germany.

$\left.{ }^{3}\right)$ Johann Heinrich von Thünen-Institut für Weltforstwirtschaft, Leuschnerstraße 91, D-21031 Hamburg, Germany.

4) Instituto de Silvicultura e Industria de la Madera, Universidad Juárez del Estado de Durango, Km 5.5 Carretera Mazatlán, 34120 Durango, Mexico.

*) Corresponding Author: Fritz Bergmann.

Sollingstraße 81, D-37081 Göttingen. Tel. 0551-93578. E-Mail: Bergmann-fritz@web.de
}

tributes to this issue by addressing three questions that seem to have been ignored so far, namely whether the use of (a) different diversity measures, of (b) different components of diversity, and of (c) different genetic traits may lead to different assessements of speciesgenetic diversity relationships. For this purpose, data on species composition and genetic traits were collected from the natural regeneration of nine forest communities, which consist of three pure and six mixed tree stands located in the Thuringian forest area. The genetic traits comprised one DNA (AFLP) and five isozyme traits all of which were determined in all species. In contrast to other studies, the species diversity was determined for two components, SD (species diversity) and $\mathrm{NeS}$ (effective number of genetically distinct species), and the genetic diversity was determined for three components, TSGD (the transspecific genetic diversity taken over all species of a community), ISGD and NGS (each 
describing a special average of intraspecific genetic diversity). Each component was quantified by measures of diversity representing four orders of the Renyi/Hillfamily. The orders correspond to the degree to which prevalence of types is considered in the diversity measure (at the lowest order, known as richness, prevalence is disregarded, with increasing order, the diversity measure reports prevalent types only). In our data, the diversity measured for each genetic trait separately showed a great range of variation across traits and components of diversity even in the same stand. The choice of the diversity component thus turned out to have a substantial effect on the assessment of the level of genetic diversity within stands. This prompted more detailed studies of the relationships between species and genetic diversity. Relationships were quantified with the help of the coefficient of co-variation, and the statistical significance of the co-variations was verified through permutation tests. The co-variations between SD and TSGD were found to be generally positive and in most cases significant, but the co-variation declined with increasing orders of diversity for most of the genetic traits. In contrast, the co-variation between SD and ISGD was not consistent for the four orders of diversity. In particular, the co-variations for the highest order were found to be negative for all traits. The results of our explorative study thus demonstrate that the assessment of levels of genetic diversity within stands as well as species-genetic interrelations critically depend on the choice of the diversity component, of the order of diversity, and of the genetic trait. These observations lend support to different and even opposing hypotheses on the processes potentially generating species-genetic relationships. Therefore, strategies in the conservation of biodiversity, for example, are suggested to be related more specifically to the components and orders of diversity to be safegarded and to consider the functions of genetic traits in relation to adaptationally relevant environmental factors.

Key words: co-variation, community genetics, diversity components, genetic diversity, genetic traits, orders of diversity, species diversity, forest tree species,

\section{Introduction}

Species diversity and genetic diversity, the two most important elements of biodiversity, have for a long time been treated as separate topics, however, recent studies on community genetics and ecology have demonstrated that these two elements are interrelated in different ways (VELLEND, 2003, 2004; VELLEND and GEBER, 2005; VELLEND and ORROCK, 2009; GIBSON et al., 2012). Whereas several studies predicted parallel processes affecting species diversity and genetic diversity within species leading to similar diversity patterns (see VELLEND and ORROCK, 2009, for review and references), other authors have proposed causal relationships between these two elements of diversity in animal (e.g. KARLIN et al., 1984) and plant communities, leading to opposite diversity patterns (ВоотH and GRIME, 2003; WeHENKEL et al., 2006). An overview of studies on this topic and the relevant interpretations of the resulting data are provided by VELLEND and GeBer (2005) and GiBson et al. (2012), for example.

The relationships are usually stated without explicit justification of the particular kinds of diversity mea- sures applied, and the levels at which diversity is considered are commonly restricted to the genetic diversity within a single target species of the community and the community's species diversity. By design such studies are limited to communities in which the target species is sufficiently abundant. Aspects of variation in abundance of the target species up to its absence altogether are not of primary concern in this design. Moreover, communities in which the target species does not show up are excluded from the study even though they may share the remaining species spectrum. Furthermore it cannot be ruled out that the genetic diversity of the target species shows relationships with the species diversity that may basically differ from the relationships realized for the non-target species. This was already noted in a simulation study by VELLEND (2005). Additionally, the effects of interactions between species that are due to genetic differences between them are ignored. In fact, such interactions are very likely to exist as a consequence of adaptational processes that take place at the community level, where selection acts within and among species. A certain confirmation of such processes was found in experimental multi-species mixtures of grasses, where an increase of genetic diversity of several species causes an increase of species diversity in several of these mixtures (FRIDLEY and GRIME, 2010).

Consideration of species-genetic interactions in communities therefore requires that study designs be extended to include genetic characteristics of all species considered in the communities under study. In order to uncover more encompassing characteristics of these interactions, it is advisable to include communities that vary in both number of species (species diversity) and species composition up to complete distinctness in species composition between communities. This entails a perspective of genetic diversity that transcends the species boundaries and by this could be appropriately addressed by a measure called "transspecific genetic diversity" (GREGORIUS et al., 2003). The measure combines the interspecific differences in genetic structure and diversity into one value, which can be used to characterize the community's genetic diversity for each genetic trait separately.

Moreover, the distribution of species and genetic types in communities is usually uneven, so that prevalent species and types can be distinguished from recedent ones. This is what one naturally expects, at least as a result of inter- and intraspecific interactions among community members. Diversity measures must therefore take account of this aspect by providing for different orders of diversity. In fact, the three most frequently applied measures, richness (number of types), the Shannon index, and Simpson's index, are known to increasingly (in this succession) reflect only prevalent types and thus higher orders of diversity (HILL, 1973; PATIL and TAILliE, 1982; Jost, 2007).

It was recently called to attention by GREGORIUS (2010) that there are also different components of diversity that refer to the distribution of genetic diversity across species. Among these are the total genetic diversity of the community (the aforementioned transspecific genetic diversity), the average genetic diversity within 
the species of a community (the intraspecific genetic diversity), the effective number of genetically distinct species, the joint species-genetic diversity, and the effective number of genetic types per species (joint diversity divided by species diversity). The joint diversity summarizes a community's genetic and species diversity most comprehensively. Since all components of diversity draw from the joint genetic and species distribution, it becomes evident that the measure applied to the joint distribution ought to be applied to all components in order to guarantee comparability of the levels of diversity. This principle of analysis is disobeyed in community genetic studies, where, for example, species diversity is measured in terms of species richness and genetic diversity is measured as "expected heterozygosity" (the conceptually consistent equivalent of which is Simpson's index of allelic diversity).

The aim of the present paper is to study relationships between species diversity and genetic diversity that can be obtained from consideration of different orders and components of diversity in eight forest tree stands representing different communities (comprising five forest associations). The genetic diversity was determined for each of six genetic traits that were selected from different molecular categories. We did not follow the common usage of averaging diversities over genetic traits, since this procedure would mask trait-specific effects on relationships with species diversity.

The present study is exploratory in that we seek clues as to what kind of cause-effect relations our methods could reveal. We therefore refrain from structuring our observations in ways that would have allowed testing of a specific preconceived cause-effect hypothesis. Compatibility of the results with common theories of community genetics is discussed, and alternatives resulting from our exploration are suggested. Extending the genetic data used in an earlier diversity analysis of the stands (WEHENKEL et al., 2006), special emphasis is now put on the explanatory power of the components of diversity as well as their performance at different orders.

\section{Material and Methods}

\section{Material}

The plant material used in this study belongs to three pure and six mixed forest stands consisting of six tree species in different proportions. The species can be assigned to five forest tree communities according to PoтT (1992) of the Thuringian (Germany) forest area (for further details, see WEHENKEL et al., 2006). Each of the nine stands was subdivided into six plots (with a radius of $7 \mathrm{~m}$ ), which were separated by a distance of about $40 \mathrm{~m}$. Most of the natural regeneration of trees in these plots (in total about 5000 individuals) was investigated. Besides the three climax species (Abies alba, Picea abies, Fagus sylvatica) two pioneer species (Betula pendula, Pinus sylvestris) and one so-called admixed tree species (Acer pseudoplatanus) were investigated in this study. The occurrence of these tree species in the nine stands and their sample sizes used for the genetic surveys were described in detail in WEHENKEL et al., (2006).

\section{Genetic traits}

Starch gel electrophoresis was used to assay five enzyme systems: aspartate aminotransferase (AAT, E.C. 2.6.1.1), phosphoglucose isomerase (PGI, E.C. 5.1.3.9), isocitrate dehydrogenase (IDH, E.C. 1.1.1.42), malate dehydrogenase $(\mathrm{MDH}$, E.C. 1.1.1.37) and hexokinase (HEK, E.C. 2.7.1.1). In most cases, dormant buds were homogenized with a dithiothreitol-based buffer and these homogenates were directly subjected to the starch gels. Further details on electrophoretic procedures and staining methods were given by KONNERT and MAURER (1995).

For the analysis of AFLPs, a selective PCR amplification of restriction fragments from a total digest of genomic DNA was used, as described by Vos et al. (1995). The genomic DNA was extracted from dormant buds by the QIAGEN DNeasy96 plant kit. AFLP traits were assayed as previously described by MARKUSSEN et al. (2005) using AFLP primers with an extension of one nucleotide. Corresponding to the definition of transspecific genetic traits (GREGORIUs et al., 2003), the same AFLP primer combination was applied to nuclear genomic DNA of all species analysed in this study.

The isozyme and AFLP patterns of all individuals are regarded as genetic traits without reference to their particular modes of inheritance. Modes of inheritance with their associated specification of allelic states are irrelevant in transspecifically defined genetic traits, since tests of (meiotic) homology are inhibited by non-crossability of individuals from different species (see GREGORIUS et al., 2003). The five enzyme systems assayed are under multilocus control, so that the differences in the isozyme patterns of each system among individuals result from allelic variation at one or several loci. Similarly, the AFLP patterns are also based on several DNA fragments (loci) and the differences among individuals result from the presence/absence state of the amplified fragments (dominant traits). In this way, isozyme and AFLP traits of all tree species show variation of several gene loci. Consequently, the measurement of the genetic diversity of individual species in the forest communities was based on isozyme and AFLP patterns as primary trait states that differ from each other solely for genetic reasons. The assessment of the genetic diversity within our communities is based on the variation in functionally homologous isozyme and sequentially homologous AFLP patterns that is observed on the level of the total community (and thus across species TSGD) and on the level of individual species. The latter level results from taking appropriate averages over the diversity data from single species (ISGD, NGS). The combining of isozyme variation data over species is no unusual method in species-genetic diversity studies, since it has been used in earlier investigations (e. g. KARLIN et al., 1984).

\section{Diversity Analysis}

There are two major aspects that are basically involved in any study concerned with finding interrelations between genetic diversity and species diversity in a community: order of diversity and component of diversity. 
Orders of diversity allow for the possibility that types (genetic or referring to species affiliation) enter an analysis of diversity with different impact depending on their rarity or prevalence (as explicitly addressed by PATIL and TAILLIE, 1982). In essence, at higher orders the effect of less frequent types on diversity is reduced (or the effect of more frequent types is enhanced). The most familiar family of measures considering orders of diversity is va as specified by

$$
v_{a}=\left(\sum p_{i}^{a}\right)^{\frac{1}{1-a}}
$$

where $a$ takes values ranging from zero to infinity and $p_{i}$ is the relative frequency of the $i$-th type. As $a$ increases, for uneven frequencies $v_{a}$ decreases while successively diminishing the effect of rare variants. The paper of HiLl (1973) is probably the first to suggest this family for diversity analyses. Since the family is a simple transformation of the information measures derived by RENYI (1961) it will be referred to as Renyi diversity. Among the most frequently applied orders in population genetics and community ecology are richness (number of types), the Shannon index $\left(-\sum p_{i} \log p_{i}\right)$, and Simpson's index $\left(1-\sum p^{2}\right)$. They represent increasing orders in this sequence, and, after appropriate transformation, they correspond to $v_{0}, v_{1}$, and $v_{2}$ in the $v_{a}$ family, where $\log v_{1}=-\Sigma p_{i} \log p_{i}$ and $v_{2}=1-\Sigma p_{i}^{2}$.

When natural numbers equal to or greater than 2 are considered for orders of diversity, $v_{a}$ has a particular interpretation based on the probability of obtaining at least two different types in a sample of size $a$ taken with replacement. In fact, $v_{a}$ equals the effective number of types corresponding to this probability. Since in most studies including our own, samples are taken without replacement, it is meaningful not to consider orders of diversity that come close to or even exceed the sample size. The sample and community sizes in our study all are well above thirty, so that we decided to analyze effects of order at four levels, $a=0, a=1, a=2$, and $a=30$.
The primary components of diversity are genetic and species specific, where genetic diversity can be further partitioned into diversity within species and diversity at the level of the total community (the notation of the components of diversity is summarized in Table 1). Determination of genetic diversity of the total community has to be based on genetic traits that are defined across species. Such genetic traits will be called transspecific and are discussed in some detail in GREGORIUS et al. (2003). Species affiliation and genetic type are tied together by their joint distribution, the diversity of which defines another component that will be referred to as the joint (species-genetic) diversity JSGD (or SGD). Species diversity (SD) and total or transspecific genetic diversity (TSGD or GD) of a community then appear as marginal diversities of JSGD. Accordingly, JSGD is always greater than or equal to both SD and TSGD, with equality only if either all species are genetically distinct (JSGD =TSGD) or if all species are genetically monomorphic (JSGD=SD). In our data, all species turned out to be genetically distinct for all genetic traits, so that JSGD = TSGD.

Special attention has to be given to the component that addresses genetic diversity within species since it is meant to summarize the genetic diversities within the individual species into a single value. This value is treated as a genetic characteristic of the species spectrum of the community and is conventionally conceived of as an average. There are basically two ways of summarizing the genetic diversity within species. One approach consists in determining the number of genetic types in each species, then taking the sum of these numbers over species and dividing it by the number of species. This is referred to as the "effective number of genetic types per species" or NGS, and it implies that all combinations of genetic type and species affiliation present in the community are counted and then divided by the number of species. Hence, NGS=JSGD/SD (see Table 1).

Table 1. - Diversity components and their general relations.

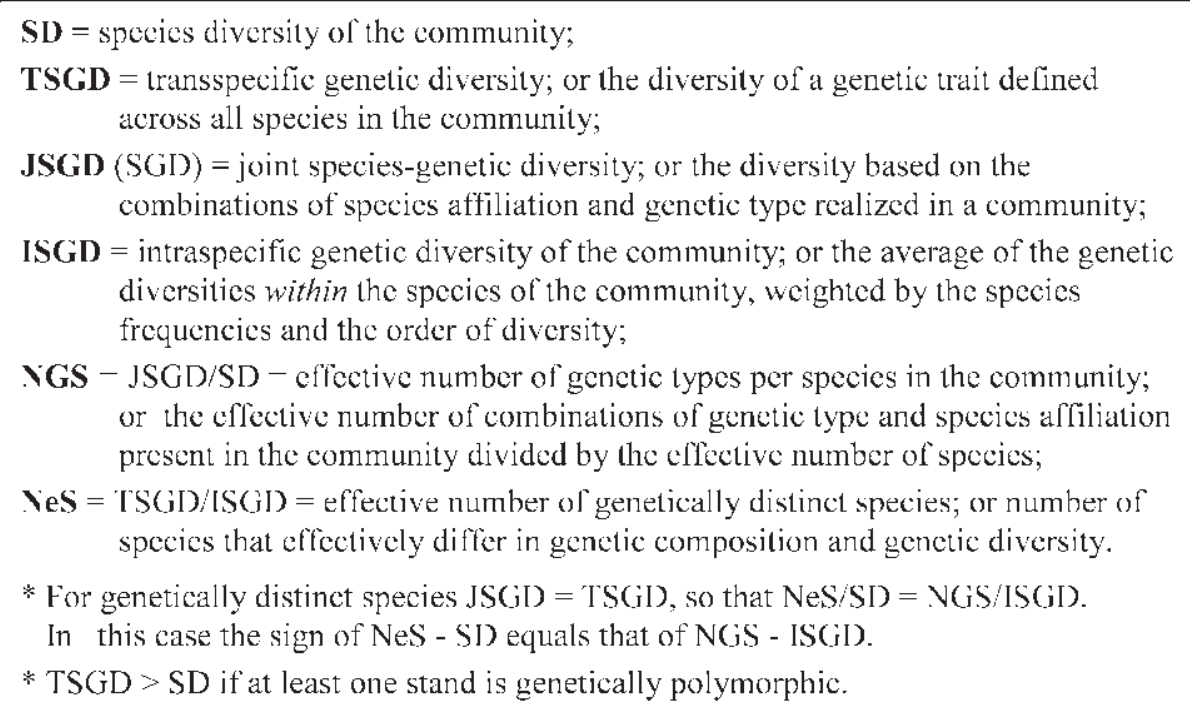


In another approach, the (linear) average of the number of genetic types found in each species is taken, where the species may be given different weights such as corresponding to their abundances. This approach reflects the common view of forming weighted averages and its measure will be called the intraspecific genetic diversity ISGD (see Table 1). Both the NGS and ISGD approach yield the same result when attributing equal weight to all species. While this holds for order $a=0$ it may change for unequal species frequencies and higher orders of measuring diversity. First of all, when measuring ISGD at different orders, the plain linear average has to be replaced by an order-specific average called power mean or Hölder mean (GREGORIUS, 2010). This mean guarantees that it does not exceed the TSGD and becomes equal to ISGD only if all species are genetically identical. It furthermore implies that NGS = ISGD for all orders if species are equally abundant, and that this identity holds for arbitrary species abundances at order $a=1$ i.e. for the measure $v_{1}$ (GREGORIUS, 2010).

Finally, there is a diversity component that addresses the genetic differences between species in terms of the effective number of genetically distinct species (NeS) and that relates to the concept of beta-diversity in community ecology (JosT, 2007). In the first place, NeS is an extended kind of species diversity that reflects genetic differences between species. Thus genetically identical species count as a single species, while the effective number of genetically distinct species increases with the degree of genetic difference between them. Genetic difference includes diversity differences between the species. NeS is defined by TSGD/ISGD, and it can be smaller or larger than the effective number of species $\mathrm{SD}$, even in the situation of genetically distinct species. However, for the order $a=1$ it follows from the above explanations that $\mathrm{NeS}=\mathrm{SD}$ in the situation of genetically distinct species. Order $a=1$ thus does not account for differences in genetic diversity between genetically distinct species. More generally, the situation of genetically distinct species implies JSGD $=$ TSGD and thus $\mathrm{NeS} / \mathrm{SD}=\mathrm{NGS} / \mathrm{ISGD}$. In other words, the relation between the two species diversities $\mathrm{NeS}$ and SD equals the relation between the two intraspecific genetic diversities NGS and ISGD. In particular, $\mathrm{NeS}>\mathrm{SD}$ is equivalent to NGS > ISGD in this case. The above relationships between diversity components that are characteristic of Renyi diversities are summarized in Table 2.

Associations between components of diversity: In many ecological hypotheses community size (in terms of number of community members) is considered as a fundamental factor limiting species and genetic diversity. Since TSGD includes the species diversity for genetically distinct species, one is therefore interested in associa- tions between community size and TSGD in the first place. More detailed information can then be extracted from associations between SD and TSGD. Most ecological hypotheses about the association between genetic and species diversity, however, are based on the genetic diversity within species. For this reason our analysis will include SD-ISGD and SD-NSG in addition to the aforementioned associations. In this paper we will not consider associations between the genetically qualified species diversity $\mathrm{NeS}$ and components of genetic diversity, since this would not allow for comparisons with established community genetic hypotheses.

To provide for the high likelihood, that the associations of interest are not linear, we computed an appropriate coefficient of co-variation in addition to the standard product-moment correlation. This coefficient was shown by GREGORIUs et al. (2007) to encompass all monotonous relations between two variables irrespective of their degree of linearity. It has the form

$$
C=\frac{\sum\left(X_{i}-X_{j}\right) \cdot\left(Y_{i}-Y_{j}\right)}{\sum\left|X_{i}-X_{j}\right| \cdot\left|Y_{i}-Y_{j}\right|}
$$

where $X$ and $Y$ denote the two variables of interest.

Permutation analysis: In order to test for the possibility that the observed relations between genetic and species diversity could have resulted from chance events governing the distribution of both types of diversity over the communities (represented by the stands), a permutation analysis is appropriate. According to the abovementioned associations of interest, the two variables to be permuted over stands are community size and TSGD, as well as species diversity and each of the three genetic diversities, TSGD, ISGD, and NGS.

\section{Results \\ Diversities}

The species diversity and the genetic diversity measured by the five components in the nine forest stands are compiled in the Tables $3 a$ to $3 f$, where the values are listed separately for four orders of diversity ( $a=0, a=1$, $a=2$, and $a=30$ ). The number of species per stand is given by the SD values for $a=0$. The highest species diversity was realized in stand 8 , and this held true consistently across all orders of diversity.

The genetic diversity of the nine forest communities (stands) measured across species by the diversity component TSGD indicates a trait-specific ranking, in that the enzymes IDH and MDH showed the smallest values (Table 3d, 3e), whereas the DNA trait AFLP showed the by far greatest values (Table 3f). Based on the sum of

Table 2. - Relations between diversity components for special orders of Renyi-diversity.

$$
\begin{aligned}
& \text { TSGD } \geq \text { ISGD for all orders } \\
& \text { ISGD - NGS for order } a-1 \\
& \text { ISGD NGS for all orders if all species are equally frequent } \\
& \text { NeS SD for order } a \quad 1 \text { if all species are genetically distinet }
\end{aligned}
$$


Table $3 a$. - Diversity values for AAT measured by the five components and four orders in 9 stands.

\begin{tabular}{|c|c|c|c|c|c|c|c|c|c|c|}
\hline \multicolumn{11}{|c|}{ AAT } \\
\hline \multicolumn{2}{|c|}{ stand size } & \multirow{2}{*}{$\begin{array}{c}872 \\
\text { Stand } 1\end{array}$} & \multirow{2}{*}{$\begin{array}{c}344 \\
\text { Stand } 2\end{array}$} & \multirow{2}{*}{$\begin{array}{c}417 \\
\text { Stand } 3\end{array}$} & \multirow{2}{*}{$\begin{array}{c}397 \\
\text { Stand } 4\end{array}$} & \multirow{2}{*}{$\begin{array}{c}1116 \\
\text { Stand } 5\end{array}$} & \multirow{2}{*}{$\begin{array}{c}206 \\
\text { Stand } 6\end{array}$} & \multirow{2}{*}{$\begin{array}{c}654 \\
\text { Stand } 7\end{array}$} & \multirow{2}{*}{$\begin{array}{c}402 \\
\text { Stand } 8\end{array}$} & \multirow{2}{*}{$\begin{array}{c}818 \\
\text { Stand } 9\end{array}$} \\
\hline Order & Index & & & & & & & & & \\
\hline \multirow[t]{5}{*}{$a=0$} & TSGD & 10.000 & 4.000 & 11.000 & 22.000 & 3.000 & 6.000 & 35.000 & 20.000 & 14.000 \\
\hline & SD & 3.000 & 1.000 & 2.000 & 2.000 & 1.000 & 1.000 & 3.000 & 3.000 & 2.000 \\
\hline & ISGD & 3.802 & 4.000 & 5.067 & 14.043 & 3.000 & 6.000 & 6.966 & 9.771 & 3.342 \\
\hline & $\mathrm{NeS}$ & 2.630 & 1.000 & 2.171 & 1.567 & 1.000 & 1.000 & 5.024 & 2.047 & 4.189 \\
\hline & NGS & 3.333 & 4.000 & 5.500 & 11.000 & 3.000 & 6.000 & 11.667 & 6.667 & 7.000 \\
\hline \multirow[t]{5}{*}{$a=1$} & TSGD & 5.025 & 2.956 & 4.422 & 12.933 & 2.424 & 3.818 & 9.134 & 13.939 & 3.305 \\
\hline & SD & 1.793 & 1.000 & 1.279 & 1.857 & 1.000 & 1.000 & 2.302 & 2.421 & 1.193 \\
\hline & ISGD & 2.802 & 2.956 & 3.457 & 6.965 & 2.424 & 3.818 & 3.968 & 5.757 & 2.770 \\
\hline & $\mathrm{NeS}$ & 1.793 & 1.000 & 1.279 & 1.857 & 1.000 & 1.000 & 2.302 & 2.421 & 1.193 \\
\hline & NGS & 2.802 & 2.956 & 3.457 & 6.965 & 2.424 & 3.818 & 3.968 & 5.757 & 2.770 \\
\hline \multirow[t]{5}{*}{$a=2$} & TSGD & 3.837 & 2.696 & 3.457 & 9.086 & 2.259 & 3.215 & 5.857 & 10.947 & 2.660 \\
\hline & SD & 1.489 & 1.000 & 1.143 & 1.747 & 1.000 & 1.000 & 1.988 & 2.100 & 1.089 \\
\hline & ISGD & 2.491 & 2.696 & 3.022 & 3.907 & 2.259 & 3.215 & 3.151 & 3.730 & 2.512 \\
\hline & $\mathrm{NeS}$ & 1.541 & 1.000 & 1.144 & 2.326 & 1.000 & 1.000 & 1.858 & 2.935 & 1.059 \\
\hline & NGS & 2.577 & 2.696 & 3.024 & 5.200 & 2.259 & 3.215 & 2.946 & 5.214 & 2.442 \\
\hline \multirow[t]{5}{*}{$a=30$} & TSGD & 2.536 & 2.195 & 2.699 & 4.850 & 2.132 & 2.539 & 3.664 & 5.628 & 2.143 \\
\hline & SD & 1.257 & 1.000 & 1.075 & 1.468 & 1.000 & 1.000 & 1.558 & 1.615 & 1.046 \\
\hline & ISGD & 2.005 & 2.195 & 2.142 & 1.503 & 2.132 & 2.539 & 2.108 & 1.470 & 2.051 \\
\hline & $\mathrm{NeS}$ & 1.265 & 1.000 & 1.260 & 3.228 & 1.000 & 1.000 & 1.739 & 3.829 & 1.045 \\
\hline & NGS & 2.017 & 2.195 & 2.512 & 3.305 & 2.132 & 2.539 & 2.352 & 3.486 & 2.048 \\
\hline
\end{tabular}

Table 3b. - Diversity values for HEK measured by the five components and four orders in 9 stands.

\begin{tabular}{|c|c|c|c|c|c|c|c|c|c|c|}
\hline \multicolumn{11}{|c|}{ HEK } \\
\hline \multicolumn{2}{|c|}{ stand size } & \multirow{2}{*}{ Stand 1} & \multirow{2}{*}{$\begin{array}{c}344 \\
\text { Stand } 2\end{array}$} & \multirow{2}{*}{$\begin{array}{c}417 \\
\text { Stand } 3\end{array}$} & \multirow{2}{*}{$\begin{array}{c}397 \\
\text { Stand } 4\end{array}$} & \multirow{2}{*}{$\begin{array}{c}1116 \\
\text { Stand } 5\end{array}$} & \multirow{2}{*}{$\begin{array}{c}206 \\
\text { Stand } 6\end{array}$} & \multirow{2}{*}{$\begin{array}{c}654 \\
\text { Stand } 7\end{array}$} & \multirow{2}{*}{$\begin{array}{c}402 \\
\text { Stand } 8\end{array}$} & \multirow{2}{*}{$\begin{array}{c}818 \\
\text { Stand } 9\end{array}$} \\
\hline Order & Index & & & & & & & & & \\
\hline \multirow[t]{5}{*}{$a=0$} & TSGD & 9.000 & 3.000 & 4.000 & 21.000 & 5.000 & 4.000 & 20.000 & 18.000 & 12.000 \\
\hline & SD & 3.000 & 1.000 & 2.000 & 2.000 & 1.000 & 1.000 & 3.000 & 3.000 & 2.000 \\
\hline & ISGD & 3.273 & 3.000 & 2.866 & 12.972 & 5.000 & 4.000 & 3.492 & 8.296 & 3.257 \\
\hline & $\mathrm{NeS}$ & 2.750 & 1.000 & 1.396 & 1.619 & 1.000 & 1.000 & 5.727 & 2.170 & 3.685 \\
\hline & NGS & 3.000 & 3.000 & 2.000 & 10.500 & 5.000 & 4.000 & 6.667 & 6.000 & 6.000 \\
\hline \multirow[t]{5}{*}{$a=1$} & TSGD & 3.918 & 2.100 & 1.982 & 13.179 & 3.039 & 1.423 & 4.319 & 9.297 & 3.437 \\
\hline & SD & 1.793 & 1.000 & 1.279 & 1.857 & 1.000 & 1.000 & 2.302 & 2.421 & 1.193 \\
\hline & ISGD & 2.185 & 2.100 & 1.549 & 7.097 & 3.039 & 1.423 & 1.876 & 3.840 & 2.880 \\
\hline & $\mathrm{NeS}$ & 1.793 & 1.000 & 1.279 & 1.857 & 1.000 & 1.000 & 2.302 & 2.421 & 1.193 \\
\hline & NGS & 2.185 & 2.100 & 1.549 & 7.097 & 3.039 & 1.423 & 1.876 & 3.840 & 2.880 \\
\hline \multirow[t]{5}{*}{$a=2$} & TSGD & 2.426 & 1.707 & 1.485 & 9.809 & 2.412 & ..1. & 2.504 & 6.180 & 2.830 \\
\hline & SD & 1.489 & 1.000 & 1.143 & 1.747 & 1.000 & 1.000 & 1.988 & 2.100 & 1.089 \\
\hline & ISGD & 1.720 & 1.707 & 1.275 & 4.626 & 2.412 & 1.176 & 1.431 & 2.624 & 2.667 \\
\hline & $\mathrm{NeS}$ & 1.411 & 1.000 & 1.165 & 2.120 & 1.000 & 1.000 & 1.751 & 2.355 & 1.061 \\
\hline & NGS & 1.629 & 1.707 & 1.299 & 5.614 & 2.412 & 1.176 & 1.260 & 2.943 & 2.598 \\
\hline \multirow[t]{5}{*}{$a=30$} & TSGD & 1.634 & 1.362 & 1.238 & 5.539 & 1.755 & 1.089 & 1.695 & 3.147 & 2.244 \\
\hline & SD & 1.257 & 1.000 & 1.075 & 1.468 & 1.000 & 1.000 & 1.558 & 1.615 & 1.046 \\
\hline & ISGD & 1.127 & 1.362 & 1.090 & 2.133 & 1.755 & 1.089 & 1.104 & 1.416 & 2.148 \\
\hline & $\mathrm{NeS}$ & 1.450 & 1.000 & 1.136 & 2.597 & 1.000 & 1.000 & 1.535 & 2.223 & 1.045 \\
\hline & NGS & 1.300 & 1.362 & 1.152 & 3.774 & 1.755 & 1.089 & 1.088 & 1.949 & 2.145 \\
\hline
\end{tabular}


Table 3c. - Diversity values for MDH measured by the five components and four orders in 9 stands.

\begin{tabular}{|c|c|c|c|c|c|c|c|c|c|c|}
\hline \multicolumn{11}{|c|}{ MDH } \\
\hline \multicolumn{2}{|c|}{ stand size } & \multirow{2}{*}{$\begin{array}{c}872 \\
\text { Stand } 1\end{array}$} & \multirow{2}{*}{$\begin{array}{c}344 \\
\text { Stand } 2\end{array}$} & \multirow{2}{*}{$\begin{array}{c}417 \\
\text { Stand } 3\end{array}$} & \multirow{2}{*}{$\begin{array}{c}397 \\
\text { Stand } 4\end{array}$} & \multirow{2}{*}{$\begin{array}{c}1116 \\
\text { Stand } 5\end{array}$} & \multirow{2}{*}{$\begin{array}{c}206 \\
\text { Stand } 6\end{array}$} & \multirow{2}{*}{$\begin{array}{c}654 \\
\text { Stand } 7\end{array}$} & \multirow{2}{*}{$\begin{array}{c}402 \\
\text { Stand } 8\end{array}$} & \multirow{2}{*}{$\begin{array}{c}818 \\
\text { Stand 9 }\end{array}$} \\
\hline Order & Index & & & & & & & & & \\
\hline \multirow[t]{5}{*}{$a=0$} & TSGD & 17.000 & 3.000 & 8.000 & 10.000 & 13.000 & 3.000 & 11.000 & 15.000 & 11.000 \\
\hline & SD & 3.000 & 1.000 & 2.000 & 2.000 & 1.000 & 1.000 & 3.000 & 3.000 & 2.000 \\
\hline & ISGD & 4.837 & 3.000 & 4.000 & 3.859 & 13.000 & 3.000 & 3.159 & 4.719 & 8.700 \\
\hline & $\mathrm{NeS}$ & 3.514 & 1.000 & 2.000 & 2.591 & 1.000 & 1.000 & 3.482 & 3.179 & 1.264 \\
\hline & NGS & 5.667 & 3.000 & 4.000 & 5.000 & 13.000 & 3.000 & 667 & 5.000 & .500 \\
\hline \multirow[t]{5}{*}{$a=1$} & TSGD & 3.387 & 1.639 & 2.349 & 4.005 & 6.723 & 1.641 & 4.404 & 5.474 & 5.197 \\
\hline & SD & 1.793 & 1.000 & 1.279 & 1.857 & 1.000 & 1.000 & 2.302 & 2.421 & 1.193 \\
\hline & ISGD & 1.889 & 1.639 & 1.837 & 2.157 & 6.723 & 1.641 & 1.913 & 2.261 & 4.355 \\
\hline & $\mathrm{NeS}$ & 1.793 & 1.000 & 1.279 & 1.857 & 1.000 & 1.000 & 2.302 & 2.421 & 1.193 \\
\hline & NGS & 1.889 & 1.639 & 1.837 & 2.157 & 6.723 & 1.641 & 1.913 & 2.261 & 4.355 \\
\hline \multirow[t]{5}{*}{$a=2$} & TSGD & 1.846 & 1.380 & 1.575 & 2.853 & 4.565 & 1.334 & 2.781 & 3.396 & 3.728 \\
\hline & SD & 1.489 & 1.000 & 1.143 & 1.747 & 1.000 & 1.000 & 1.988 & 2.100 & 1.089 \\
\hline & ISGD & 1.398 & 1.380 & 1.426 & 1.753 & 4.565 & 1.334 & 1.571 & 1.721 & 3.281 \\
\hline & $\mathrm{NeS}$ & 1.320 & 1.000 & 1.104 & 1.627 & 1.000 & 1.000 & 1.770 & 1.136 & 1.136 \\
\hline & NGS & 1.240 & 1.380 & 1.378 & 1.633 & 4.565 & 1.334 & 1.399 & 1.618 & 3.423 \\
\hline \multirow[t]{5}{*}{$a=30$} & TSGD & 1.385 & 1.200 & 1.277 & 1.886 & 2.921 & 1.170 & 1.789 & 2.034 & 2.620 \\
\hline & SD & 1.257 & 1.000 & 1.075 & 1.468 & 1.000 & 1.000 & 1.558 & 1.615 & 1.046 \\
\hline & ISGD & 1.110 & 1.200 & 1.191 & 1.302 & 2.921 & 1.170 & 1.165 & 1.200 & 1.557 \\
\hline & $\mathrm{NeS}$ & 1.247 & 1.000 & 1.072 & 1.449 & 1.000 & 1.000 & 1.535 & 1.695 & 1.683 \\
\hline & NGS & 1.102 & 1.200 & 1.189 & 1.285 & 2.921 & 1.170 & 1.148 & 1.260 & 2.504 \\
\hline
\end{tabular}

TSGDs over stands calculated for $a=1$, the diversity ranking of genetic traits from smallest to largest is IDH (20.8), MDH (34.8), PGI (41.1), HEK (42.7), AAT (58.0), $\operatorname{AFLP}(208.2)$.

For orders different from $a=1$, the two components ISGD and NGS of genetic diversity within species differed for all genetic traits in stands with more than one species. In several cases NGS outvalued ISGD more than double. But there still existed cases where ISGD $>$ NGS. Ranking of stands varied between ISGD and NGS on the basis of traits and of orders. NGS is slightly more consistent across orders. Thus, the choice of the diversity component has a substantial effect on the assessment of the average genetic diversity within species. Average diversity within species is also more sensitive than TSGD to genetic trait and order of diversity.

In addition to the complete genetic distinction, species differed substantially in their (intraspecific) genetic diversity characteristics. This became apparent from the fact that, for orders distinct from $a=1$, NeS differed from $\mathrm{SD}$ in almost all cases despite the complete genetic distinctness among the species.

\section{Co-variations between genetic and species diversities}

Potential relationships between genetic and species diversities in the nine forest stands were determined by two measures of co-variation. One of them was the coef- ficient of co-variation $C$ as specified above, the values of which and the degree of significance ( $p$-values) are listed in Table 4 for each of the six genetic traits separately. The second measure was the classical product moment correlation, which is however not reported since it yielded fewer significant results due to its restriction to the detection of linear relationships. Co-variations are consistent with the $p$-values in that small co-variation (close to zero) goes along with $p$-values close to 0.5 , while co-variations become increasingly positive with $p$-values increasingly falling below 0.5 , and co-variations become increasingly negative with $p$-values increasingly rising above 0.5 .

The co-variations $C$ between the transspecific genetic diversity (TSGD) and the species diversity (SD) were found to be generally positive and in most cases significant or highly significant. On the other hand, the values decreased with increasing orders a for all traits, with the exception of AAT and PGI. The strongest reduction of these values was observed for $\mathrm{MDH}$ where for orders $a>0$ the co-variation was positive but far from significant, and it was even close to zero for $a=30$.

In contrast to these observations, the co-variation between the intraspecific genetic diversity (ISGD) and $\mathrm{SD}$ is not consistent for the four orders of diversity, since the values for $a=30$ are negative for all traits, with IDH and $\mathrm{MDH}$ exhibiting negative co-variations also for other orders (Table 4). Beyond that, most of the co-varia- 
Table $3 d$. - Diversity values for IDH measured by the five components and four orders in 9 stands.

\begin{tabular}{|c|c|c|c|c|c|c|c|c|c|c|}
\hline \multicolumn{11}{|c|}{ IDH } \\
\hline \multicolumn{2}{|c|}{ stand size } & \multirow{2}{*}{$\begin{array}{c}872 \\
\text { Stand 1 }\end{array}$} & \multirow{2}{*}{$\begin{array}{c}344 \\
\text { Stand } 2\end{array}$} & \multirow{2}{*}{$\begin{array}{c}417 \\
\text { Stand } 3\end{array}$} & \multirow{2}{*}{$\begin{array}{c}397 \\
\text { Stand } 4\end{array}$} & \multirow{2}{*}{$\begin{array}{c}1116 \\
\text { Stand } 5\end{array}$} & \multirow{2}{*}{$\begin{array}{c}206 \\
\text { Stand } 6\end{array}$} & \multirow{2}{*}{$\begin{array}{c}654 \\
\text { Stand } 7\end{array}$} & \multirow{2}{*}{$\begin{array}{c}402 \\
\text { Stand } 8\end{array}$} & \multirow{2}{*}{$\begin{array}{c}818 \\
\text { Stand } 9\end{array}$} \\
\hline Order & Index & & & & & & & & & \\
\hline \multirow{5}{*}{$a=0$} & TSGD & 8.000 & 2.000 & 5.000 & 5.000 & 3.000 & 2.000 & 9.000 & 6.000 & 4.000 \\
\hline & SD & 3.000 & 1.000 & 2.000 & 2.000 & 1.000 & 1.000 & 3.000 & 3.000 & 2.000 \\
\hline & ISGD & 2.198 & 2.000 & 2.067 & 2.310 & 3.000 & 2.000 & 2.428 & 2.152 & 2.000 \\
\hline & $\mathrm{NeS}$ & 3.639 & 1.000 & 2.419 & 2.165 & 1.000 & 1.000 & 3.707 & 2.788 & 2.000 \\
\hline & NGS & 2.667 & 2.000 & 2.500 & 2.500 & 3.000 & 2.000 & 3.000 & 2.000 & 2.000 \\
\hline \multirow[t]{5}{*}{$a=1$} & TSGD & 2.521 & 1.086 & 1.520 & 3.578 & 2.238 & 1.084 & 2.837 & 3.898 & 2.073 \\
\hline & SD & 1.793 & 1.000 & 1.279 & 1.857 & 1.000 & 1.000 & 2.302 & 2.421 & 1.193 \\
\hline & ISGD & 1.406 & 1.086 & 1.189 & 1.927 & 2.238 & 1.084 & 1.232 & 1.610 & 1.738 \\
\hline & $\mathrm{NeS}$ & 1.793 & 1.000 & 1.279 & 1.857 & 1.000 & 1.000 & 2.302 & 2.421 & 1.193 \\
\hline & NGS & 1.793 & 1.086 & 1.189 & 1.927 & 2.238 & 1.084 & 1.232 & 1.610 & 1.738 \\
\hline \multirow[t]{5}{*}{$a=2$} & TSGD & 1.707 & 1.033 & 1.207 & 3.064 & 2.101 & 1.032 & 2.094 & 3.012 & 1.742 \\
\hline & SD & 1.489 & 1.000 & 1.143 & 1.747 & 1.000 & 1.000 & 1.988 & 2.100 & 1.089 \\
\hline & ISGD & 1.225 & 1.033 & 1.092 & 1.734 & 2.101 & 1.032 & 1.112 & 1.435 & 1.580 \\
\hline & $\mathrm{NeS}$ & 1.393 & 1.000 & 1.105 & 1.767 & 1.000 & 1.000 & 1.883 & 2.099 & 1.103 \\
\hline & NGS & 1.146 & 1.033 & 1.056 & 1.754 & 2.101 & 1.032 & 1.053 & 1.435 & 1.599 \\
\hline \multirow[t]{5}{*}{$a=30$} & TSGD & 1.340 & 1.017 & 1.104 & 2.197 & 1.893 & 1.016 & 1.584 & 1.956 & 1.409 \\
\hline & SD & 1.257 & 1.000 & 1.075 & 1.468 & 1.000 & 1.000 & 1.558 & 1.615 & 1.046 \\
\hline & ISGD & 1.074 & 1.017 & 1.030 & 1.378 & 1.893 & 1.016 & 1.028 & 1.078 & 1.244 \\
\hline & $\mathrm{NeS}$ & 1.247 & 1.000 & 1.072 & 1.595 & 1.000 & 1.000 & 1.540 & 1.814 & 1.133 \\
\hline & NGS & 1.066 & 1.017 & 1.027 & 1.497 & 1.893 & 1.016 & 1.016 & 1.211 & 1.347 \\
\hline
\end{tabular}

Table 3e. - Diversity values for PGI measured by the five components and four orders in 9 stands.

\begin{tabular}{|c|c|c|c|c|c|c|c|c|c|c|}
\hline \multicolumn{11}{|c|}{ PGI } \\
\hline \multicolumn{2}{|c|}{ stand size } & \multirow{2}{*}{$\begin{array}{c}872 \\
\text { Stand } 1\end{array}$} & \multirow{2}{*}{$\begin{array}{c}344 \\
\text { Stand } 2\end{array}$} & \multirow{2}{*}{$\begin{array}{c}417 \\
\text { Stand } 3\end{array}$} & \multirow{2}{*}{$\begin{array}{c}397 \\
\text { Stand } 4\end{array}$} & \multirow{2}{*}{$\begin{array}{c}1116 \\
\text { Stand } 5\end{array}$} & \multirow{2}{*}{$\begin{array}{c}206 \\
\text { Stand } 6\end{array}$} & \multirow{2}{*}{$\begin{array}{c}654 \\
\text { Stand } 7\end{array}$} & \multirow{2}{*}{$\begin{array}{c}402 \\
\text { Stand } 8\end{array}$} & \multirow{2}{*}{$\begin{array}{c}818 \\
\text { Stand } 9\end{array}$} \\
\hline Order & Index & & & & & & & & & \\
\hline \multirow[t]{5}{*}{$a=0$} & TSGD & 9.000 & 4.000 & 5.000 & 16.000 & 2.000 & 4.000 & 26.000 & 18.000 & 11.000 \\
\hline & SD & 3.000 & 1.000 & 2.000 & 2.000 & 1.000 & 1.000 & 3.000 & 3.000 & 2.000 \\
\hline & ISGD & 4.405 & 4.000 & 2.933 & 10.662 & 2.000 & 4.000 & 6.630 & 9.400 & 2.300 \\
\hline & $\mathrm{NeS}$ & 2.043 & 1.000 & 1.705 & 1.501 & 1.000 & 1.000 & 3.922 & 1.915 & 4.784 \\
\hline & NGS & 3.000 & 4.000 & 2.500 & 8.000 & 2.000 & 4.000 & 8.667 & 6.000 & 5.500 \\
\hline \multirow[t]{5}{*}{$a=1$} & TSGD & 4.265 & 2.606 & 3.272 & 7.286 & 1.211 & 2.373 & 8.698 & 10.005 & 1.393 \\
\hline & SD & 1.793 & 1.000 & 1.279 & 1.857 & 1.000 & 1.000 & 2.302 & .421 & 1.193 \\
\hline & ISGD & 2.378 & 2.606 & 2.558 & 3.924 & 1.211 & 2.373 & 3.778 & 4.133 & 1.167 \\
\hline & $\mathrm{NeS}$ & 1.793 & 1.000 & 1.279 & 1.857 & 1.000 & 1.000 & 2.302 & 2.421 & 1.193 \\
\hline & NGS & 2.378 & 2.606 & 2.558 & 3.924 & 1.211 & 2.373 & 3.778 & 133 & 1.167 \\
\hline \multirow[t]{5}{*}{$a=2$} & TSGD & 3.434 & 2.341 & 2.789 & 4.000 & 1.100 & 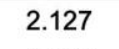 & 5.000 & 6.881 & 1.124 \\
\hline & SD & 1.489 & 1.000 & 1.143 & 1.747 & 1.000 & 1.000 & 1.988 & 2.100 & 1.089 \\
\hline & ISGD & 1.939 & 2.341 & 2.333 & 2.171 & 1.100 & 2.127 & 2.872 & 2.365 & 1.066 \\
\hline & $\mathrm{NeS}$ & 1.771 & 1.000 & 1.196 & 2.302 & 1.000 & 1.000 & 1.741 & 2.910 & 1.054 \\
\hline & NGS & 2.306 & 2.341 & 2.440 & 2.861 & 1.100 & 2.127 & 2.515 & 3.278 & 1.031 \\
\hline \multirow[t]{5}{*}{$a=30$} & TSGD & 2.615 & 2.266 & 2.144 & 3.360 & 1.052 & 1.813 & 2.909 & 4.009 & 1.062 \\
\hline & SD & 1.257 & 1.000 & 1.075 & 1.468 & 1.000 & 1.000 & 1.558 & 1.615 & 1.046 \\
\hline & ISGD & 1.080 & 2.266 & 1.337 & 1.041 & 1.052 & 1.813 & 1.895 & 1.047 & 1.017 \\
\hline & $\mathrm{NeS}$ & 2.421 & 1.000 & 1.603 & 3.227 & 1.000 & 1.000 & 1.535 & 3.827 & 1.045 \\
\hline & NGS & 1.257 & 2.266 & 1.995 & 2.289 & 1.052 & 1.813 & 1.867 & 2.483 & 1.015 \\
\hline
\end{tabular}


Table 3f. - Diversity values for AFLP measured by the five components and four orders in 9 stands.

\begin{tabular}{|c|c|c|c|c|c|c|c|c|c|c|}
\hline \multicolumn{11}{|c|}{ AFLP } \\
\hline \multicolumn{2}{|c|}{ stand size } & 872 & 344 & 417 & 397 & 1116 & 206 & 654 & 402 & 818 \\
\hline Order & Index & Stand 1 & Stand 2 & Stand 3 & Stand 4 & Stand 5 & Stand 6 & Stand 7 & Stand 8 & Stand 9 \\
\hline \multirow[t]{5}{*}{$a=0$} & TSGD & 59.000 & 19.000 & 28.000 & 47.000 & 22.000 & 19.000 & 46.000 & 64.000 & 36.000 \\
\hline & SD & 3.000 & 1.000 & 2.000 & 2.000 & 1.000 & 1.000 & 3.000 & 3.000 & 2.000 \\
\hline & ISGD & 25.275 & 19.000 & 19.194 & 20.647 & 22.000 & 19.000 & 19.654 & 18.836 & 23.487 \\
\hline & $\mathrm{NeS}$ & 2.334 & 1.000 & 1.459 & 2.276 & 1.000 & 1.000 & 2.340 & 3.398 & 1.533 \\
\hline & NGS & 19.667 & 19.000 & 14.000 & 23.500 & 22.000 & 19.000 & 15.333 & 21.333 & 18.000 \\
\hline \multirow[t]{5}{*}{$a=1$} & TSGD & 33.868 & 13.361 & 5 & 8 & 66 & 09 & 41 & 1.701 & 16.774 \\
\hline & SD & 1.793 & 1.000 & 1.279 & 1.857 & 1.000 & 1.000 & 2.302 & 2.421 & 1.193 \\
\hline & ISGD & 18.885 & 13.361 & 15.780 & 16.149 & 16.106 & 13.209 & 14.353 & 13.094 & 14.057 \\
\hline & $\mathrm{NeS}$ & 1.793 & 1.000 & 1.279 & 1.857 & 1.000 & 1.000 & 2.302 & 2.421 & 1.193 \\
\hline & NGS & 18.885 & 13.361 & 15.780 & 16.149 & 16.106 & 13.209 & 14.353 & 13.094 & 14.057 \\
\hline \multirow[t]{5}{*}{$a=2$} & TSGD & 24.101 & 10.223 & 16.091 & 21.871 & 12.212 & 10.449 & 26.167 & 16.912 & 8.747 \\
\hline & SD & 1.489 & 1.000 & 1.143 & 1.747 & 1.000 & 1.000 & 1.988 & 2.100 & 1.089 \\
\hline & ISGD & 14.386 & 10.223 & 12.585 & 13.302 & 12.212 & 10.449 & 10.868 & 9.060 & 8.080 \\
\hline & $\mathrm{NeS}$ & 1.675 & 1.000 & 1.279 & 1.644 & 1.000 & 1.000 & 2.408 & 1.867 & 1.083 \\
\hline & NGS & 16.186 & 10.223 & 14.075 & 12.518 & 12.212 & 10.449 & 13.163 & 8.055 & 8.030 \\
\hline \multirow[t]{5}{*}{$a=30$} & TSGD & 10.029 & 5.468 & 7.450 & 11.325 & 6.083 & 6.182 & 12.046 & 5.997 & 3.528 \\
\hline & SD & 1.257 & 1.000 & 1.075 & 1.468 & 1.000 & 1.000 & 1.558 & 1.615 & 1.046 \\
\hline & ISGD & 3.512 & 5.468 & 3.273 & 7.721 & 6.083 & 6.182 & 2.525 & 3.774 & 3.377 \\
\hline & $\mathrm{NeS}$ & 2.855 & 1.000 & 2.277 & 1.467 & 1.000 & 1.000 & 4.771 & 1.589 & 1.045 \\
\hline & NGS & 7.978 & 5.468 & 6.933 & 7.717 & 6.083 & 6.182 & 7.732 & 3.715 & 3.372 \\
\hline
\end{tabular}

tion values were relatively small, only AAT and PGI showed a few significant values. An extreme inversion occurred for AAT, where for orders $a=1$ and $a=2$ the ISGD-SD co-variation is strongly and significantly positive, while for $a=30$ it is strongly and significantly negative. The situation for PGI is similar though slightly less drastic.

The co-variations between NGS and SD showed a different trend, in that the values were positive and partly significant for the traits AAT, PGI and HEK, whereas the values were small, partly negative and non-significant for the traits IDH, MDH and AFLP (Table 4). MDH showed the smallest co-variations for TSGD-SD, whereas both, MDH and IDH, showed the smallest values of the co-variations ISGD-SD and NGS-SD. This goes along with the generally low genetic diversities of these traits within the tree species considered in our study. Consequently, the diversity components ISGD and NGS (i.e. the two "average diversities") did not show marked variations for these traits. AFLP was found to possess the highest genetic diversity values, however, it showed similarly small covariations between ISGD-SD and NGS-SD. Only the genetic traits with intermediate genetic diversities across species exhibited greater positive or negative covariations. Between orders of diversity no strong inversions in co-variation between NGS and SD occurred such as observed for the co-variations between ISGD and SD.
Both a decline of ISGD and a rise of NGS went along with increasing species diversity for traits AAT, PGI, HEK and AFLP at the order $a=30$. These opposing tendencies for ISGD and NGS were highly significant in both directions for AAT. Another non-significant opposing tendency was realized for IDH and AFLP at order $a=0$. In all of these cases the effective number of genetically distinct species $\mathrm{NeS}$ distinctly exceeded SD in at least one stand. Since all species were genetically distinct, the observation $\mathrm{NeS}>\mathrm{SD}$ is equivalent to NGS > ISGD. Hence, if NGS is smaller than or equal to ISGD across stands, the co-variation of the two "average diversities" with species diversity is found to point in the same direction.

To provide for the possibility that the overall genetic diversity TSGD is primarily determined by the number of individuals observed across all species in each of the stands, the co-variation between this number $(\mathrm{N}$, see Table 4) and TSGD was analysed. With one exception, none of the genetic traits showed significant co-variation, so that species diversity rather than stand size is significantly involved in the co-variation with TSGD. The exception is $\mathrm{MDH}$, for which a strong and highly significant positive co-variation existed between $\mathrm{N}$ and TSGD. This goes along with the only case of weak covariation between species diversity and TSGD as well as with the only case of negative co-variations of both "average diversities" (ISGD, NGS) with species diversity across all orders of diversity. 
Table 4. - Covariations (C).

\begin{tabular}{|c|c|c|c|c|c|c|c|c|c|}
\hline $\begin{array}{c}\text { genetic } \\
\text { trait }\end{array}$ & order & TSGD $\sim \mathrm{SD}$ & p-value & ISGD SD & p-value & NGS $\sim \mathrm{SD}$ & $p$-value & $\mathrm{N} \sim \mathrm{TSGD}$ & $p$-value \\
\hline AAT & $\begin{array}{c}0 \\
1 \\
2 \\
30\end{array}$ & $\begin{array}{l}0,9249 \\
0,9777 \\
0,9816 \\
0,9854\end{array}$ & $\begin{array}{l}0,0134 \\
0,0020 \\
0,0017 \\
0,0015\end{array}$ & $\begin{array}{c}0,5154 \\
0,8406 \\
0,8511 \\
-0,9517\end{array}$ & $\begin{array}{l}0,2019 \\
\mathbf{0 , 0 3 7 8} \\
\mathbf{0 , 0 2 8 7} \\
\mathbf{0 , 9 8 9 6}\end{array}$ & $\begin{array}{l}0,6062 \\
0,8406 \\
0,8909 \\
0,8450\end{array}$ & $\begin{array}{l}0,1441 \\
\mathbf{0 , 0 3 8 6} \\
\mathbf{0 , 0 3 1 5} \\
\mathbf{0 , 0 3 9 9}\end{array}$ & $\begin{array}{l}-0,1390 \\
-0,5486 \\
-0,6117 \\
-0,6451\end{array}$ & $\begin{array}{l}0,5705 \\
0,8139 \\
0,8368 \\
0,8537\end{array}$ \\
\hline PGI & $\begin{array}{c}0 \\
1 \\
2 \\
30\end{array}$ & $\begin{array}{l}0,9556 \\
0,9934 \\
0,9934 \\
0,9829\end{array}$ & $\begin{array}{l}0,0062 \\
0,0005 \\
0,0003 \\
0,0009\end{array}$ & $\begin{array}{c}0,7332 \\
0,9538 \\
0,8548 \\
-0,3569\end{array}$ & $\begin{array}{l}0,0897 \\
\mathbf{0 , 0 0 7 1} \\
\mathbf{0 , 0 5 0 2} \\
0,7051\end{array}$ & $\begin{array}{l}0,6765 \\
0,9538 \\
0,9587 \\
0,9538\end{array}$ & $\begin{array}{l}0,0942 \\
\mathbf{0 , 0 0 6 8} \\
\mathbf{0 , 0 0 4 5} \\
\mathbf{0 , 0 0 6 8}\end{array}$ & $\begin{array}{l}-0,0967 \\
-0,4536 \\
-0,5416 \\
-0,6319\end{array}$ & $\begin{array}{l}0,5470 \\
0,7853 \\
0,8275 \\
0,8941\end{array}$ \\
\hline HEK & $\begin{array}{c}0 \\
1 \\
2 \\
30\end{array}$ & $\begin{array}{l}0,8873 \\
0,8868 \\
0,8818 \\
0,8574\end{array}$ & $\begin{array}{l}0,0282 \\
0,0278 \\
0,0446 \\
0,0500\end{array}$ & $\begin{array}{c}0,2626 \\
0,5743 \\
0,5292 \\
-0,0214\end{array}$ & $\begin{array}{l}0,4116 \\
0,1951 \\
0,2034 \\
0,5087\end{array}$ & $\begin{array}{l}0,3486 \\
0,5743 \\
0,5619 \\
0,5480\end{array}$ & $\begin{array}{l}0,2925 \\
0,1991 \\
0,1989 \\
0,2201\end{array}$ & $\begin{array}{l}-0,0289 \\
-0,2957 \\
-0,3254 \\
-0,2558\end{array}$ & $\begin{array}{l}0,5120 \\
0,6528 \\
0,6502 \\
0,5816\end{array}$ \\
\hline IDH & $\begin{array}{c}0 \\
1 \\
2 \\
30\end{array}$ & $\begin{array}{l}1,0000 \\
0,9665 \\
0,9358 \\
0,8353\end{array}$ & $\begin{array}{l}0,0004 \\
0,0020 \\
0,0079 \\
0,0323\end{array}$ & $\begin{array}{c}-0,1576 \\
0,0447 \\
-0,0112 \\
-0,4134\end{array}$ & $\begin{array}{l}0,5658 \\
0,4648 \\
0,4878 \\
0,6560\end{array}$ & $\begin{array}{c}0,3463 \\
0,0447 \\
-0,0500 \\
-0,1834\end{array}$ & $\begin{array}{l}0,2907 \\
0,4613 \\
0,5181 \\
0,5485\end{array}$ & $\begin{array}{l}0,3627 \\
0,2227 \\
0,2107 \\
0,4158\end{array}$ & $\begin{array}{l}0,2506 \\
0,3409 \\
0,3555 \\
0,2220\end{array}$ \\
\hline $\mathrm{MDH}$ & $\begin{array}{c}0 \\
1 \\
2 \\
30\end{array}$ & $\begin{array}{l}0,8852 \\
0,4450 \\
0,2916 \\
0,0609\end{array}$ & $\begin{array}{l}\mathbf{0 , 0 1 5 9} \\
0,2036 \\
0,3019 \\
0,4654\end{array}$ & $\begin{array}{l}-0,4587 \\
-0,6708 \\
-0,6537 \\
-0,8648\end{array}$ & $\begin{array}{l}0,7423 \\
0,7728 \\
0,7477 \\
0,8801\end{array}$ & $\begin{array}{l}-0,3694 \\
-0,6708 \\
-0,7606 \\
-0,8407\end{array}$ & $\begin{array}{l}0,6674 \\
0,7750 \\
0,7858 \\
0,8303\end{array}$ & $\begin{array}{l}0,8686 \\
0,8692 \\
0,8277 \\
0,8573\end{array}$ & $\begin{array}{l}0,0209 \\
0,0173 \\
0,0289 \\
0,0243\end{array}$ \\
\hline AFLP & $\begin{array}{c}0 \\
1 \\
2 \\
30\end{array}$ & $\begin{array}{l}0,9980 \\
0,9872 \\
0,9050 \\
0,8133\end{array}$ & $\begin{array}{l}0,0012 \\
0,0006 \\
0,0119 \\
0,0385\end{array}$ & $\begin{array}{c}0,3814 \\
0,1013 \\
0,0459 \\
-0,3053\end{array}$ & $\begin{array}{l}0,2639 \\
0,4135 \\
0,4733 \\
0,6779\end{array}$ & $\begin{array}{c}-0,2829 \\
0,1013 \\
0,0627 \\
0,2256\end{array}$ & $\begin{array}{l}0,6850 \\
0,4115 \\
0,4537 \\
0,3596\end{array}$ & $\begin{array}{r}0,1687 \\
0,1651 \\
0,1500 \\
-0,0192\end{array}$ & $\begin{array}{l}0,3853 \\
0,3910 \\
0,3926 \\
0,5031\end{array}$ \\
\hline
\end{tabular}

p-value $=$ proportion of C-values among 10000 permutations that are equal to or greater than the observed $\mathrm{C}$-value. TSGD = transspecific genetic diversity, $\mathrm{SD}=$ species diversity, ISGD = intraspecific genetic diversity, NGS = genetic diversity per species, $\mathrm{N}=$ number of individuals in stand.

\section{Discussion}

It has become clear from the above that the two most important elements of biodiversity, species diversity and genetic diversity, can be assessed for different aspects, so that, depending on the biological and ecological objectives in mind, the most appropriate aspect can be chosen. In our study, the species diversity was determined by two diversity components (SD, NeS) and four orders of diversity, whereas the genetic diversity was measured by three components (TSGD, ISGD, NGS) and also four orders of diversity (Table 3). The question now arose, as to whether species diversity and genetic diversity both assessed in the nine forest stands vary independently across the tree communities, and if this is not the case, which type of relationship can be discovered by our methods. Because of the complexity and novelty of our results the following discussion will be organized into two sections (A) and (B), where (A) concentrates on questions relating to the diversity characteristics of the individual stands as summarized in Table 3 , and (B) treats questions concerning relationships between components of species diversity and components of genetic diversity that show up across the stands (summarized in terms of co-variations in Table 4).

\section{(A) Diversity characteristics of stands}

The respective values of diversity vary among stands and among genetic traits, and in most cases also among components of diversity. Furthermore, a characteristic feature of Renyi diversity is the decline of the values with increasing orders of diversity. When comparing the isozyme traits, PGI, AAT and HEK revealed generally higher diversities than IDH and $\mathrm{MDH}$. One reason for these differences may be found in patterns of genetic variation known to be typical for these traits in the tree species studied. Whereas type frequencies of AAT, PGI and occasionally HEK occur as so-called major polymorphism in most of the tree species, minor polymorphisms were more often found for IDH and MDH. In population genetics, a major polymorphism is realized at a gene locus if two or three of its alleles occur in similar frequencies. This entails higher diversity estimates than obtainable for a minor polymorphism with one dominant and several rare alleles (see GREGORIUS and BERGMANN, 1995 for further details). More specific aspects are addressed with the help of the following questions as indicated above.

\section{(1) Does the genetic diversity differ between stands with respect to genetic trait and order of diversity?}

The genetic diversity differs among the nine stands for all diversity components, however, the range of these differences depends on the particular genetic trait. Whereas the among-stand differences are relatively small for $\mathrm{MDH}$ and IDH, they are larger for AAT and PGI and reach very high values for the AFLP trait (Table $3 a-f$ ). This corresponds to the general degrees of polymorphism. Although the diversity values decrease with higher orders, the ranking of stands for the diversities remains the same for most stands. For some stands, however, their ranking changes because of differences in evenness of the frequency profiles of genetic types within stands. This is especially the case for higher orders of diversity such as $a=2$ and $a=30$, which accords with the 
fact that profiles with low evenness show large differences between orders. In conclusion, the level of genetic diversity within stands depends on the respective type of genetic trait, but the resulting ranking of stands with respect to the trait-specific diversity is largely stable across the four orders of diversity. The few cases of inconsistent ranking are due to higher degrees of unevenness of the frequency profiles.

\section{(2) Are there stands with extreme genetic diversity across all traits?}

Consistently high genetic diversity across all genetic traits in all species of a community is very likely to be the result of high degrees of recent immigration or invasion. Particularly in less isolated communities this situation may affect all resident species equally. At the other extreme, the consistently low genetic diversity found across all traits in all species hints at a recent bottleneck experienced by the whole community. Since bottlenecks preferentially eliminate rare genetic types, one expects this phenomenon to be observable chiefly for low orders of diversity.

There is no stand with consistently highest genetic diversity values across all genetic traits, rather several stands with two or three tree species (stands $4,7,8,9$ ) exhibit in general higher diversity values for TSGD than stands with only one species. This result is self-evident for order $a=0$, but it is also consistent for orders $a=2$ and $a=30$. In contrast to TSGD, the two components ISGD and NGS measuring the intraspecific genetic diversity reveal no clear relationship to the number of species within the stands or to particular genetic traits.

When comparing the diversity data among those stands which contain only one species, the number of individuals affects the MDH diversities to a certain degree (Table 3c). This result concerns the three components as well as the four orders of diversity, suggesting a particular relationship between $\mathrm{MDH}$ diversity and the size of species as was also documented by the significantly positive co-variations in Table 4 (see section B). In conclusion, a consistently high or low genetic diversity across all traits in all species could not be observed, so that the assumption of recent waves of immigration or of a recent bottleneck does not seem to apply to our stands.

\section{(3) Do stands differ for the ranking of genetic diversity components?}

According to the explanations in the Methods section, the non-trivial comparisons are between the two intraspecific diversities ISGD and NGS, and between TSGD and NGS. As to the latter, we observe TSGD $\geq$ NGS in all stands for each trait and each order of diversity. On this level, NGS and ISGD thus both do not exceed TSGD even though the inequality TSGD $\geq$ NGS need not hold in general (GREGORIUS, 2010, middle of p.390).

This is in sharp contrast with the ranking of the two intraspecific genetic diversities ISGD and NGS. There is no apparently consistent ranking across stands, neither with respect to genetic trait nor with respect to order of diversity. It is therefore not surprising that the ranking of stands is found to differ between the two diversity components for all traits and orders of diversity. The latter statement reminds of the fact that the assessment of the genetic diversity of the species of a community may strongly depend both on the kind (order) of measure of genetic diversity and on the kind of "averaging" over species. Elaboration of the forces that differentiate between these measures and components requires more analysis than can be provided in this paper.

\section{(B) Relationships between species diversity and components of genetic diversity.}

Most of the current hypotheses about relationships between genetic and species diversity can be classified into any one of the following three categories: genetic diversity affects species diversity, species diversity affects genetic diversity, both are (independently) affected by a third agent. In an ecological context the first two categories address internal relationships within a community while the third category includes an external component that affects internal relationships. This categorization is familiar in the statistics of (causal) relationships between two variables, where the external component in the third category is referred to as establishing "spurious relationships" between the two variables if it escapes observation.

Internal and external effects can be characterized in terms of environmental conditions, where internal environmental (or milieu) conditions include as a special case the conditions that are provided to one species by its interactions with the other species in the community. The hypothesis of parallel effects as treated in several of the above-cited papers belongs to the third category. It assumes that an external factor determines both diversities in the same direction, so that the two diversities co-vary positively.

According to SILvERTOwN et al. (2009), the niche variation hypothesis predicts that populations with few interspecific competitors and hence broader niches are expected to contain greater genetic diversity. Thus, the existence of few competitors implies low species diversity, and this is presumed to allow for high genetic diversity in the prevailing species. As a consequence one expects a negative correlation between species diversity and genetic diversity. In contrast, the coexistence hypothesis (AARSSEN, 1983) predicts that high intraspecific genetic diversity favours coexistence among species leading to a relatively high species diversity and therefore species and genetic diversity should be positively correlated (see also FRIDLEY and GRIME, 2010). Both hypotheses are based on internal effects, however, they point into opposite directions. Causal relations are not explicitly specified.

External environmental heterogeneity is frequently considered to be a major driving force of biological diversity, even though the relevant environmental factors and their effective scale are mostly difficult to identify in observational studies. Model simulations indicate that environmental heterogeneity in combination with norms of reaction that vary genetically within species as 
well as between species may serve to explain positive as well as negative relationships between genetic and species diversity (see e.g. VELLEND, 2005, and especially GiBson et al., 2012). These studies again focus on the genetic diversity within a single target species.

Since for genetically distinct species the ratio of the two species diversities $\mathrm{SD}$ and $\mathrm{NeS}$ equals the ratio of the two intraspecific genetic diversities NGS and ISGD, it is sufficient to consider relationships between SD and the components of genetic diversity. This is also advisable for drawing connections to established theories and experimental results on relationships between species diversity and genetic diversity.

The co-variations between the total genetic diversity in the community (TSGD) and the species diversity (SD) are generally positive and in most cases significant or highly significant (Table 4). In view of the fact that all species were genetically distinct for all genetic traits this appears obvious, since in this case more species are expected to add more genetic variation to the community. This positive co-variation is not related to the size of the tree stand, since the co-variations between $\mathrm{N}$ and TSGD were found to be negative or positive and non-significant with the exception of $\mathrm{MDH}$, the latter showing significantly strong positive co-variation at all orders of diversity. On top of this, $\mathrm{MDH}$ is the only trait with negative co-variation between species diversity SD and both components of intraspecific genetic diversity across all orders of diversity. This is quite remarkable since $\mathrm{MDH}$ is the only genetic trait that is known to be encoded by several minorpolymorphic isozymes (loci) across the species studied.

\section{(1) Do relationships between species diversity and the components of genetic diversity depend on order of diversity?}

In contrast to the TSGD-SD co-variations, the ISGDSD co-variations appear to be particularly remarkable since they are negative for the order $a=30$ across all genetic traits (Table 4). One explanation may be the decline of effective number of genetic types within the species along with the increase of the effective number of prevalent species. However, this cannot support the so-called trade-off hypothesis, since drift effects could not be observed for the lower orders of diversity ( $a=1$, $a=0$ ). Opposing the tendency observed for ISGD-SD covariations, the NGS-SD co-variations do not show negative values for the traits AAT, PGI and HEK. This can be explained by the tendency that at higher orders $(a=30)$ NGS can be large if the most frequent species show high diversity for prevalent genetic types (major polymorphisms in dominant species). On the other hand, NGS may become small at these orders if the most frequent species reveal low diversity for prevalent genetic types (minor polymorphisms in dominant species), which is the case for the traits $\mathrm{MDH}$ and partly IDH.

\section{(2) Do relationships between species diversity and the components of genetic diversity depend on trait?}

Although the co-variations TSGD-SD are qualitatively consistent among the six genetic traits, the co-variations between both components of intraspecific genetic diversity (ISGD, NGS) and SD reveal great differences among these genetic traits. Apart from the order $a=30$, the genetic traits AAT, PGI and HEK show in all cases positive and partly significant co-variation values, while co-variations between TSGD and $\mathrm{N}$ are negative. In contrast, the traits IDH and MDH frequently exhibit negative and non-significant co-variations, but show positive TSGD-N co-variation values. The DNA based trait AFLP reveals in most cases positive, but the co-variations ISGD-SD and NGD-SD are not significant (Table 4). Thus, the data of our study clearly demonstrate the particular trait-specific effects on the species-genetic diversity relationships across the nine tree communities.

(3) Which traits, orders of diversity, and components of diversity support which of the common hypotheses about relationships between genetic and species diversity?

Positive relationships between species and genetic diversity have recently been documented in several papers (e.g. VELLEND, 2003; Hu et al., 2006; He et al., 2008; VELLEND and ORROCK, 2009), and it was often maintained that this is the result of evolutionary processes that have influenced the two diversities in the same direction (ANTONOVICS, 1992, 2003). This so-called parallelism hypothesis was supported by studies on habitat and/or community size which affect both species diversity and genetic diversity of the prevalent species in the same manner leading to a positive correlation between the two diversities (e.g. VELLEND, 2004). It is conceivable that external factors, such as space or other limiting resources, may also limit community size and this can reasonably be expected to affect the overall community diversity covering genetic and species diversity. In contrast to these studies, it was recently shown that generalizations about parallel changes of species and genetic diversities should not be permitted, since no relationships between these diversities could be found in disturbed communities (WEI and JIANG, 2012).

In our case the overall diversity is represented by the JSGD which equals the TSGD in our study. One can therefore expect community size $\mathrm{N}$ to be one of the dominating external factors affecting community diversity in terms of TSGD. Since TSGD equals intraspecific genetic diversity times species diversity (ISGD x NeS, Table 1), the parallel effects of $\mathrm{N}$ on ISGD (NGS) and SD (NeS) should then imply positive co-variation between $\mathrm{N}$ and TSGD. However, the co-variations of TSGD with community size $(\mathrm{N})$ were found to be negative for three traits and all orders, but positive for the three other traits. Hence, the hypothesis of parallel effects arising from community size has no support in our study. In fact, the only genetic trait that showed significantly positive co-variation between TSGD and $\mathrm{N}$ across all orders of diversity (MDH) shows consistently negative co-variation between the genetic and species components of diversity.

The coexistence hypothesis also was not supported by our data, since the co-variations ISGD-SD and NGS-SD are not consistent across the genetic traits. Only the traits AAT, PGI and HEK reveal positive co-variations between intraspecific genetic diversity and species 
diversity, however, it is not very likely that only these traits will be involved in species interactions in forest tree communities. On the other hand, especially the two traits AAT and HEK were found to be involved in interspecific neighbourhood associations between particular genotypes of one species with co-occurring other species (see WEHENKEL et al., 2007). The question whether the results of our association study are related to the coexistence hypothesis in multispecies tree communities must be answered by a further investigation.

In summary it becomes apparent that in the natural regeneration of our particular set of forest communities almost all of the current hypotheses on relationships between genetic and species diversities could be confirmed to a statistically significant degree for particular genetic traits and for particular components and orders of diversity. Only one of the most frequently suggested processes, namely that of parallel effects arising from community size controlled by external factors, found no support at all in our study. It thus appears that in our study community internal factors are more likely than external factors to affect the species-genetic relationships. In particular, isozyme traits with well-known function and frequently showing major polymorphisms (AAT, PGI) were found to cause almost consistently positive co-variations between species and genetic diversity. The thus indicated adaptational significance of the two traits could turn out to be due to community internal rather than community external conditions.

This suggests for further studies to consider the possibility that the processes that determine species-genetic relationships may act in quite different and even opposing ways on different genetic traits in the same community, and that these processes may become differentially effective with respect to the components and orders of diversity considered in our study. Especially in the design of conservation strategies of biodiversity, our observations point at the necessity to argue more specifically on the component and order of the diversity to be safegarded and to consider the functions of genetic traits in relation to adaptationally relevant environmental conditions.

\section{Acknowledgments}

This study was funded by a grant Gr 435/23-1 of the Deutsche Forschungsgemeinschaft (DFG, German Research Foundation). The authors appreciate the detailed recommendations of two anonymous reviewers for impovement of the representation of our results.

\section{References}

AARssen, L.W. (1983): Ecological combining ability and competitive combining ability in plants: toward a general evolutionary theory of coexistence in systems of competition. The American Naturalist, 122 (6), 707-731.

ANTONOVICS, J. (1992): Toward community genetics. In: Fritz, R. S., Simms, E. L. (eds.). Plant Resistance to Herbivores and Pathogens: Ecology, Evolution and Genetics. University of Chicago Press, Chicago, pp. 429-449.
Antonovics, J. (2003): Toward community genomics? Ecology, 84, 598-601.

Booth, R. E. and J. P. GRIME (2003): Effects of genetic impoverishment on plant community diversity. Journal of Ecology 91, 721-733.

FRIDLEY, J. D. and J. P. GRIME (2010): Community and ecosystem effects of intraspecific genetic diversity in grassland microcosms of varying species diversity. Ecology 91, 2272-2283.

Gibson, D. J., A. J. Allstadt, S. G. Baer and M. Geisler (2012): Effects of foundation species genotypic diversity on subordinate species richness in an assembling community. Oikos 121, 496-507.

GREGORIUS, H.-R. (2010): Linking diversity and differentiation. Diversity 2, 370.

Gregorius, H.-R. and F. BERGMANN (1995): Analysis of isoenzyme genetic profiles observed in tree populations. In: Baradat, P., AdAms, W. T., MÜller-Starck (eds.). Population Genetics and Genetic Conservation of Forest Trees. SPB Academic Publishers, Amsterdam. pp. 79-96.

Gregorius, H.-R., F. Bergmann and Chr. Wehenkel (2003): Analysis of biodiversity across levels of biological organization: a problem of defining traits. Perspectives in Plant Ecology, Evolution and Systematics 5, 209-218.

Gregorius, H.-R., B. Degen and A. König (2007): Problems in the analysis of genetic differentiation among populations - a case study in Quercus robur. Silvae Genetica 56, 190-199.

He, T., B. B. Lamont, S. L. Krauss, N. J. EnRight and B. P. Miller (2008): Covariation between intraspecific genetic diversity and species diversity within a plant functional group. Journal of Ecology 96, 956-961.

HiLl, M. O. (1973): Diversity and evenness: A unifying notation and its consequences. Ecology 54, 427-432.

Hu, X.-S., F. He and S. P. HubBel (2006): Neutral theory in macroecology and population genetics. Oikos 113, $548-556$.

Jost, L. (2007): Partitioning diversity into independent alpha and beta components. Ecology 88, 2427-2439.

Karlin, A. A., W. S. Guttman and S. L. Rathbun (1984): Spatial autocorrelation analysis of heterozygosity and geographic distribution in population of Desmognathus fuscus (Amphibia: Plethodontidae). Copeia 1984, 343-356.

Konnert, M. and W. MAurer (1995): Isozymic investigations on Norway spruce (Picea abies (L.) Karst.) and European silver fir (Abies alba Mill.): A practical guide to separation methods and zymogram evaluation. Laboratory Manual (edited by the German Federal State Work Group "Conservation of Forest Genetic Resources"), pp 79.

Markussen, T., A. Tusch, B. R. Stephan and M. Fladung (2005): Identification of molecular markers for selected wood properties of Norway spruce (Picea abies L. (Karst.). II. Extractives content. Silvae Genetica 54, 145-152.

Patil, G. P. and C. TAILlie (1982): Diversity as a concept and its measurement. Journal of the American Statistical Association, 77, 548-561.

Pотт, R. (1992) Die Pflanzengesellschaften Deutschlands. Verlag Eugen Ulmer, Stuttgart.

RENYI, A. (1961) On measures of entropy and information. In: NeymanN, J. (ed.). Proceedings of the $4^{\text {th }}$ Berkeley Symposium on Mathematics, Statistics and Probability. Vol. 1. .University of California Press, Berkeley, pp. 547-561. 